\title{
Gold Alloy Dental Inlay for Preventing Involuntary Body Movements Caused by Electromagnetic Waves Emitted by a Cell Phone
}

\author{
Yoshiro Fujii \\ Director of Shin Kobe Dental Clinic, Kobe City, Japan \\ Email: shin-kobe-dentalclinic@s9.dion.ne.jp
}

Received 18 September 2014; revised 28 October 2014; accepted 17 November 2014

Copyright (C) 2014 by author and Scientific Research Publishing Inc.

This work is licensed under the Creative Commons Attribution International License (CC BY). http://creativecommons.org/licenses/by/4.0/

\section{(c) (i) Open Access}

\begin{abstract}
Cell phone and personal computer use has increased considerably in recent years, particularly in developed countries. These devices have facilitated communication on a global scale. However, there have been a number of reports of health problems related to the electromagnetic waves emitted by such electronic devices. A long list of both general and severe symptoms, including headaches, fatigue, tinnitus, dizziness, memory loss, irregular heartbeat and whole-body skin lesions, have been reported. These are reportedly associated with the condition known as electromagnetic hypersensitivity (EHS). This report shows how a subject's abnormal involuntary body movements, caused by electromagnetic waves emitted by a cell phone, are prevented by placing a gold alloy inlay in the subject's mouth. It appears that the subject's involuntary movements are the result of balance dysregulation resulting from EHS. The subject's various symptoms improve after the specific dental treatment. However, the underlying mechanism of the symptoms and the reasons why this treatment is so successful remain unknown. Further research is required to clarify these issues.
\end{abstract}

\section{Keywords}

Balance Dysregulation, Cell Phone, Electromagnetic Hypersensitivity, Involuntary Body Movement

\section{Introduction}

The use of electronic devices, such as cell phones and personal computers, has become increasingly widespread 
in recent years and enabled communication on a global scale [1] [2]. However, there is an apparent increase in the number of health problems resulting from the electromagnetic waves emitted by electronic devices, such as cell phones [3]-[10]. Physically unpleasant symptoms caused by exposure to electromagnetic waves are recognized as EHS and encompass a wide range of symptoms, including headaches, fatigue, tinnitus, dizziness, memory loss, irregular heartbeats and whole-body skin lesions [11]-[15]. This case report describes how a subject's involuntary movements, caused by electromagnetic waves, are treated using dental techniques. A gold alloy inlay was placed in a tooth within the subject's mouth to neutralize the electromagnetic waves from a cell phone and eliminate the subject's involuntary movements due to EHS.

\section{Case Report}

\section{Treatment and Results}

A 34-year-old woman was suffering from the symptoms related to a balance dysregulation, i.e. giddiness, unsteady, etc. After examining the subject, the author proposed that the symptoms were the result of EHS. An experiment was designed to test this hypothesis. Firstly, the subject was blindfolded so that the subject was unaware of what was in front of her and to minimize any confounding effects. A cell phone was held about $1 \mathrm{~m}$ away from her and an aluminum foil sheet was held between the phone and the subject to shield her from the electromagnetic waves being emitted by the phone. No involuntary movements were observed (Figure 1).

In the second test, the aluminum foil shielding was removed. The subject suddenly began to lean to the left and right involuntarily (Figure 2(a) and Figure 2(b)).

The involuntary movements stopped when the aluminum foil shielded the subject from the phone. The experiment was repeated twice and the results were similar for both tests. The subject began to lean to the left and right when the aluminum foil shielding was removed, but stopped when the shielding was replaced. The results of this experiment indicate that the subject was suffering from EHS. However, the mechanism underpinning EHS is unclear. The subject did not have any implanted materials, such as dental fillings or metal cores, to attract electromagnetic waves from devices, such as cell phones. Therefore, the author attempted to neutralize the harmfulness of the electromagnetic waves entering the subject's body by using a gold alloy as previously shown [16]. The subject had small dental caries in her right upper second molar. The author removed the caries but it was not adequate to solve the patient's symptoms problem. A week later, the author placed a gold alloy inlay containing Au 86\% and Pt 11.8\% (Figure 3) over the tooth to restore the tooth after treating the dental caries

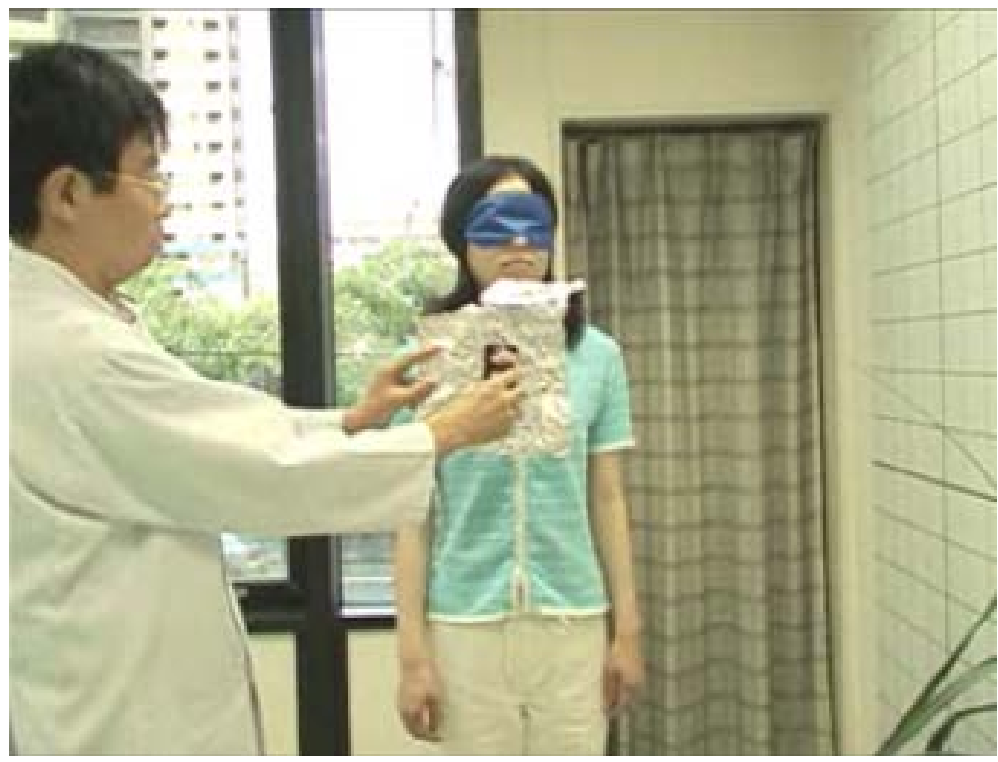

Figure 1. A cell phone was held about $1 \mathrm{~m}$ away from the blindfolded subject and aluminum foil was placed between the subject and a cell phone to shield the subject from the electromagnetic waves emitted by a cell phone. The subject's posture was normal. 


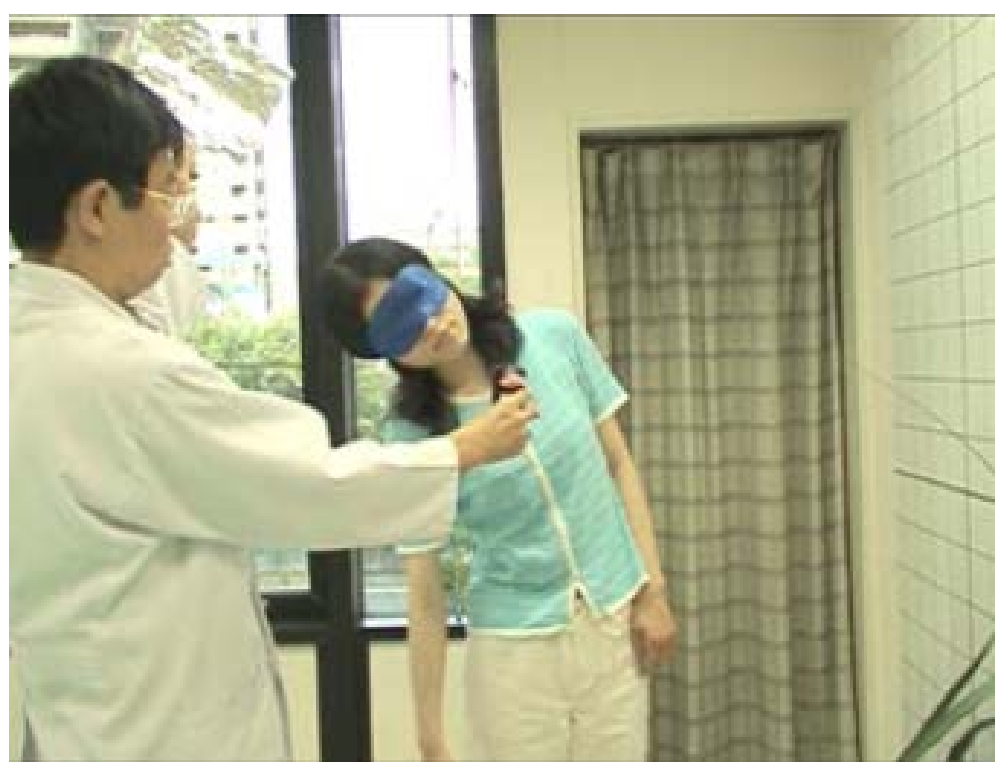

(a)

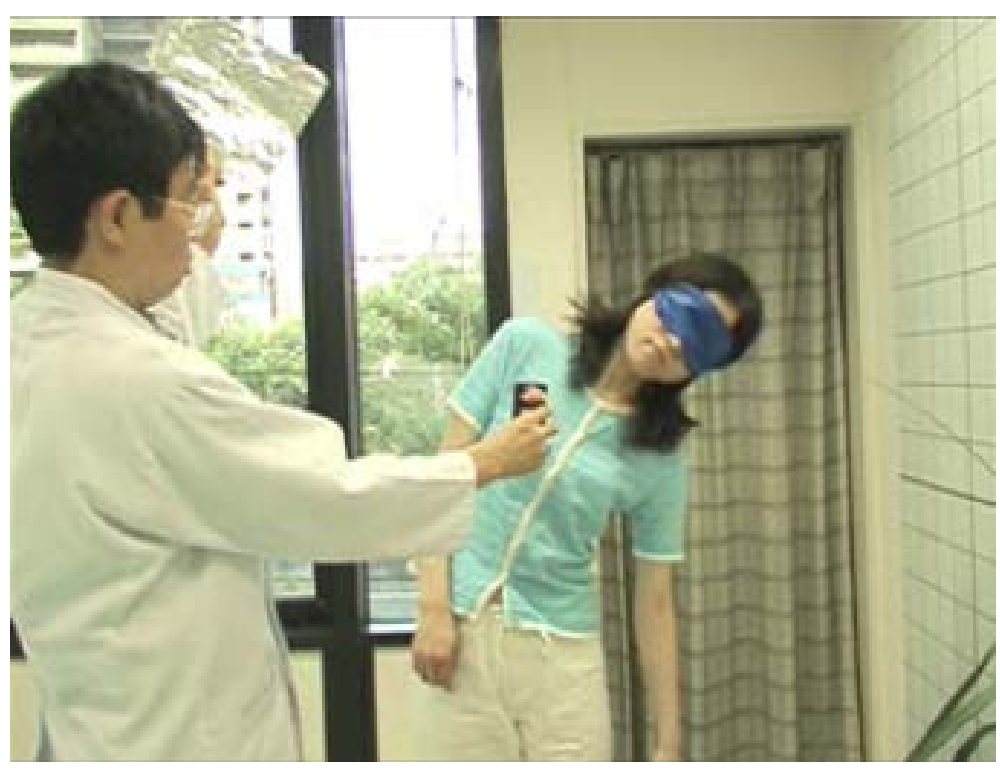

(b)

Figure 2. When aluminum foil held between the subject and the cell phone was removed, the subject's body leaned to the right or the left involuntarily.

(Figure 4). This alloy was selected using the Bi-Digital O-Ring Test [17], i.e. first, the metal sample was put on the palm of one of the subject's hands. Next, the subject was irradiated with the electromagnetic waves emitted by a cell phone. The metal was chosen if the strength of the grip of the subject's other hand did not decrease. Moreover, when a patient had this metal, it checked that her body did not move even if the patient was irradiated with electromagnetic waves emitted by a cell phone.

Shortly after the inlay was placed, the aluminum foil experiment was repeated. The subject was again blindfolded so that she could not see the position of the cell phone or the foil. Firstly, the shielded cell phone was held in front of the subject. Secondly, the shield was removed. The subject showed no physical reaction to either the shielded or unshielded cell phone. This lack of reaction seemed to indicate that the subject's EHS had been inhibited. Over the few weeks, the subject also reported that her complaints had improved. It is speculated that such improvements were likely the result of the cessation of the subject's involuntary movements. 


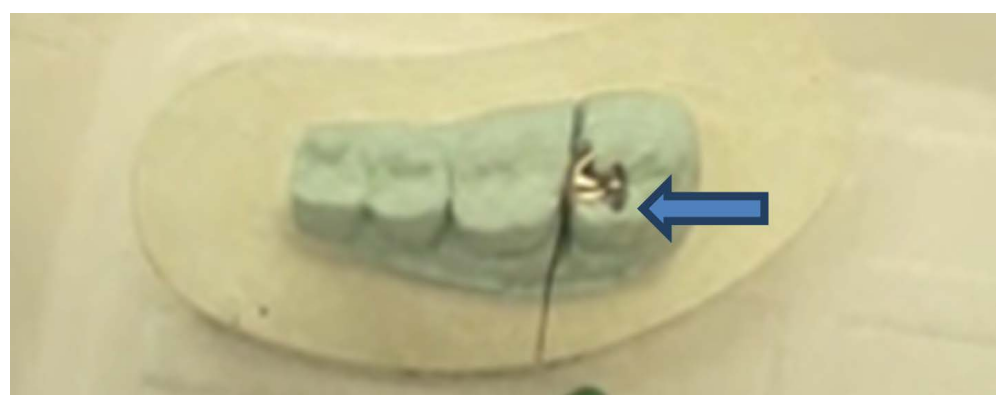

Figure 3. The arrow is pointing to a gold alloy inlay in the casting mold. This inlay was later placed in the subject's mouth.

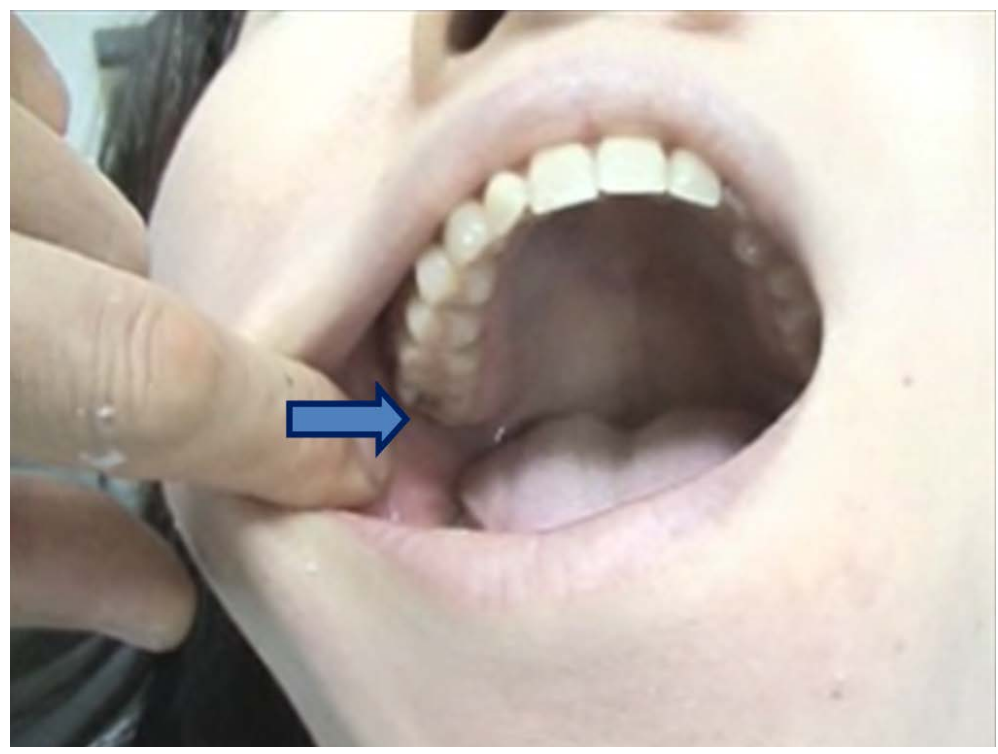

Figure 4. The arrow is pointing to the gold alloy inlay in the subject's tooth. The inlay was used to restore the dental caries on her right upper second molar.

\section{Discussion}

The author tried same examination three times with three different kinds of cell phones, respectively. However, result of these examinations was same. These cell phones' SAR (Specific Absorption Rate) is less than $2.0 \mathrm{~W} / \mathrm{kg}$ because of Japanese restriction. Therefore, there is a possibility that the result is different in other countries. In this experiment, the distance $1 \mathrm{~m}$ is situated in the Fraunh offer (far field) region, because the radio wave length of cell phones $(1-2 \mathrm{GHz})$ is $0.15-0.3 \mathrm{~m}$. The distance between cell phones and which border of near field is calculated with $\{\lambda /(2 \pi)\}$. Therefore, the distance from cell phones to the border of near field is about $2.5 \mathrm{~cm}$ to $5.0 \mathrm{~cm}$ from cell phones. Hence, $1 \mathrm{~m}$ is in the far field range. However, the difference of effects among regions on the human bodies has not been clarified yet. Therefore, further research is required.

With regard to the relationship between brain tumors and electromagnetic waves emitted by cell phones, the Interphone Study Group concluded that overall, no increase in risk of glioma or meningioma was observed with use of mobile phones. There were suggestions of an increased risk of glioma at the highest exposure levels, but biases and error prevent a causal interpretation. The possible effects of long-term heavy use of mobile phones require further investigation [18]. Moreover, The WHO/International Agency for Research on Cancer (IARC) has classified radiofrequency electromagnetic fields as possibly carcinogenic to humans (Group 2B), based on an increased risk for glioma, a malignant type of brain cancer associated with wireless phone use in 2011. Group 2B means that the agent is possibly carcinogenic to humans [19].

Other reports also do not support an association between the use of cell phones and the development of brain 
or salivary gland tumors, leukemia, or other cancers [20]-[22]. However, the research described did not sufficiently evaluate the risks among long-term heavy cell phone users over long induction periods [20]. Accordingly, further studies are needed to account for longer exposure periods, particularly with respect to slow-growing intracranial tumors [21]. The author has published several reports on the relationship between dentistry and electromagnetic waves [16] [23]-[25]. Many articles only emphasize the convenience of these electronic devices without addressing the potentially negative influences of the emitted electromagnetic waves on the body [26]. Metals present within the body can act as antennas to collect harmful electromagnetic waves and induce the aforementioned symptoms. For example, scoliosis may be caused by dental implants that collect harmful electromagnetic radiation, but that pure gold may neutralize it [16]. In addition, electromagnetic waves emitted by cell phones can also cause balance disorders [25].

The underlying mechanism remains unknown but decreased blood flow within the brain has been proposed [4]. This collection of symptoms caused by electromagnetic waves is known as electromagnetic wave hypersensitivity (EHS). In the aforementioned case, the author could not find any suspicious dental materials collecting harmful electromagnetic waves in the subject's mouth. Therefore, the author sought to neutralize and reverse the effects of the electromagnetic waves. A gold alloy inlay was set on the subject's upper second molar because the patient had mild dental caries on that tooth. Only the removal of dental caries was not effective, but the gold alloy inlay worked well. To select the proper dental alloy to neutralize the electromagnetic waves, the Bi-Digital O-Ring Test was used [17]. On the basis of previous findings, the gold may neutralize the harmfulness of the electromagnetic waves emitted by a cell phone [16]. If the subject had not had any dental caries, the author would require her to place the metal on her body. The underlying mechanism has been partially elucidated by the Bi-Digital O-Ring Test [17]. This test indicates the deleterious effects of electromagnetic waves on the body [27] [28] and may be a useful diagnostic tool for helping to prevent the harmful effects of electromagnetic waves. Hence, I used this test to select the adequate metal to solve patient's problem. However, the real mechanism of this neutralization is unclear; therefore, further study with the cooperation between medical field and physical field is required. The author's research has shown that the removal of metals that collect harmful electromagnetic waves from patients may be useful to avoid electromagnetic hypersensitivity [25]. In addition, maintaining a sufficient distance from cell phones could decrease some of the harmful effects of electromagnetic waves and may permit short-duration, lower-risk use of cell phones.

The effects of electromagnetic waves on the body are not yet clear. One potential problem with these results is that the subject's knowledge of how close they were to the electromagnetic wave sources was not controlled. This could have led to some psychological influences, because of which the subject was blindfolded in this case. According to the report of Hagström et al. (2013), the most common perceived EHS-triggering sources are personal computers and mobile phones. In addition, the best way to decrease EHS symptoms is to avoid electromagnetic fields [29]. As the author has already reported [25], it seems that there may be substances which collect harmful electromagnetic waves. On the other hand, there may be substances which neutralize them like in this case.

The neutralization of harmful electromagnetic radiation with dental fillings is not well known. Hence the treatment method introduced in this paper could become an important approach for the treatment of EHS.

\section{Conclusion}

There have been many reports of individuals suffering from EHS. The current findings suggest that, in addition to previously reported symptoms (headaches, fatigue, tinnitus, dizziness, memory loss, irregular heartbeat and skin lesion), a sense of balance dysregulation is a symptom of EHS. Avoiding harmful electromagnetic waves is considered to decrease these physical symptoms and concomitantly improve physical abilities. In some cases, the neutralization of harmful electromagnetic radiation with dental fillings may also be an effective approach to treating EHS symptoms.

\section{References}

[1] Geser, H. (2004) Towards a Sociological Theory of the Mobile Phone. Release 3.0, University of Zurich, Zurich. http://socio.ch/mobile/t geser1.htm/

[2] van Dijk, J. and Hacker, K. (2003) The Digital Divide as a Complex and Dynamic Phenomenon. The Information Society: An International Journal, 19, 315-326. http://dx.doi.org/10.1080/01972240309487 
[3] http://www.holistic-dentistry.net/blog/2013/07/entry 242/

[4] Aalto, S., Haarala, C., Brück, A., Sipilä, H., Hämäläinen, H. and Rinne, J.O. (2006) Mobile Phone Affects Cerebral Blood Flow in Humans. Journal of Cerebral Blood Flow and Metabolism, 26, 885-900. http://dx.doi.org/10.1038/sj.jcbfm.9600279

[5] Feychting, M., Jonsson, F., Pedersen, N.L. and Ahlbom, A. (2003) Occupational Magnetic Field Exposure and Neurodegenerative Disease. Epidemiology, 14, 413-419. http://dx.doi.org/10.1097/01.EDE.0000071409.23291.7b

[6] Håkansson, N., Gustavsson, P., Johansen, C. and Floderus, B. (2003) Neurodegenerative Diseases in Welders and Other Workers Exposed to High Levels of Magnetic Fields. Epidemiology, 14, 420-426. http://dx.doi.org/10.1097/01.EDE.0000078446.76859.c9

[7] Ahlbom, A. (2001) Neurodegenerative Diseases, Suicide and Depressive Symptoms in Relation to EMF. Bioelectromagnetics, Supplement 5, S132-S143.

[8] Linet, M.S., Hatch, E.E., Kleinerman, R.A., Robison, L.L., Kaune, W.T., Friedman, D.R., Severson, R.K., Haines, C.M., Hartsock, C.T., Niwa, S., Wacholder, S. and Tarone, R.E. (1997) Residential Exposure to Magnetic Fields and Acute Lymphoblastic Leukemia in Children. The New England Journal of Medicine, 337, 1-7. http://dx.doi.org/10.1056/NEJM199707033370101

[9] Röösli, M., Moser, M., Baldinini, Y., Meier, M. and Braun-Fahrländer, C. (2007) Symptoms of Ill Health Ascribed to Electromagnetic Field Exposure-A Questionnaire Survey. International Journal of Hygiene and Environmental Health, 207, 141-150. http://dx.doi.org/10.1078/1438-4639-00269

[10] Edelstyn, N. and Oldershaw, A. (2002) The Acute Effects of Exposure to the Electromagnetic Field Emitted by Mobile Phones on Human Attention. NeuroReport, 13, 119-121. http://dx.doi.org/10.1097/00001756-200201210-00028

[11] Rea, W., Pan, Y., Yenyves, E., Sujisawa, I., Suyama, H., Samadi, N. and Ross, G. (1991) Electromagnetic Field Sensitivity. Journal of Bioelectricity, 10, 241-256. http://firstdonoharmblog.blogspot.jp/2011/05/electromagnetic-field-sensitivity.html

[12] Rubin, G.J., Das Munshi, J. and Wessely, S. (2005) Electromagnetic Hypersensitivity: A Systematic Review of Provocation Studies. Psychosomatic Medicine, 67, 224-232. http://dx.doi.org/10.1097/01.psy.0000155664.13300.64

[13] Rubin, G.J., Das Munshi, J. and Wessely, S. (2006) A Systematic Review of Treatments for Electromagnetic Hypersensitivity. Psychosomatic Medicine, 75, 12-18.

[14] Norbert, L. (2009) Electromagnetic Hypersensitivity. Advances in Electromagnetic Fields in Living Systems, 5, 167197. http://dx.doi.org/10.1007/978-0-387-92736-7 5

[15] Kimata, H. (2005) Microwave Radiation from Cellular Phones Increases Allergen-Specific IgE Production. Allergy, 60, 838-839. http://dx.doi.org/10.1111/j.1398-9995.2005.00802.x

[16] Fujii, Y. (2012) Do Dental Implants Cause Scoliosis? A Case Report. Personalized Medicine Universe, 1, 79-80. http://dx.doi.org/10.1016/i.pmu.2012.05.012

[17] Omura, Y. (1990) Bi-Digital O-Ring Test for Imaging and Diagnosis of Internal Organs of a Patient. US Patent No. 5188107.

[18] Interphone Study Group (2010) Brain Tumor Risk in Relation to Mobile Telephone Use: Results of the Interphone International Case-Control Study. International Journal of Epidemiology, 39, 675-694. http://dx.doi.org/10.1093/ije/dyq079

[19] http://www.iarc.fr/en/media-centre/pr/2011/pdfs/pr208_E.pdf

[20] Johansen, C., Boice Jr., J.D., McLaughlin, J.K. and Olsen, J.H. (2001) Cellular Telephones and Cancer-A Nationwide Cohort Study in Denmark. Journal of the National Cancer Institute, 93, 203-207. http://dx.doi.org/10.1093/jnci/93.3.203

[21] Inskip, P.D., Tarone, R.E., Hatch, E.E., Wilcosky, T.C., Shapiro, W.R., Selker, R.G., Fine, H.A., Black, P.M., Loeffler, J.S. and Linet, M.S. (2001) Cellular-Telephone Use and Brain Tumors. The New England Journal of Medicine, 344, 79-86. http://dx.doi.org/10.1056/NEJM200101113440201

[22] Muscat, J.E., Malkin, M.G., Thompson, S., Shore, R.E., Stellman, S.D., McRee, D., Neugut, A.I. and Wynder, E.L. (2000) Handheld Cellular Telephone Use and Risk of Brain Cancer. Journal of the American Medical Association, 284, 3001-3007. http://dx.doi.org/10.1001/jama.284.23.3001

[23] Fujii, Y. (2007) The Dental Treatment That Used Environment of Electromagnetic Wave. Acupuncture and ElectroTherapeutics Research, 32, 291

[24] Fujii, Y. (2009) The Consideration of the Electromagnetic Wave in Dental Material Substitution. Acupuncture and Electro-Therapeutics Research, 34, 89 .

[25] Fujii, Y. (2014) Sensation of Balance Dysregulation Caused/Aggravated by a Collection of Electromagnetic Waves in 
a Dental Implant. Open Journal of Antennas and Propagation, 2, 29-35. http://dx.doi.org/10.4236/ojapr.2014.23004

[26] http://www.healthit.gov/providers-professionals/benefits-electronic-health-records-ehrs

[27] Omura, Y. and Losco, M. (1993) Electro-Magnetic Fields in the Home Environment (Color TV, Computer Monitor, Microwave Oven, Cellar Phone, etc.) as Potential Contributing Factors for the Induction of Oncogen C-Fos Ab1, Oncogen C-Fos Ab2, Integrin Alpha 5 Beta 1 and Development of Cancer, as Well as Effects of Microwave on Amino Acid Composition of Food and Living Human Brain. Acupuncture and Electro-Therapeutics Research, 18, 33-73.

[28] Omura, Y., Losco, M., Omura, A.K., Yamamoto, S., Ishikawa, H., Takeshige, C., Shimotsuura, Y. and Muteki, T. (1991) Chronic or Intractable Medical Problems Associated with Prolonged Exposure to Unsuspected Harmful Environmental Electric, Magnetic, or Electro-Magnetic Fields Radiating in the Bedroom or Workplace and Their Exacerbation by Intake of Harmful Light and Heavy Metals from Common Sources. Acupuncture and Electro-Therapeutics Research, 16, 143-177.

[29] Hagström, M., Auranen, J. and Ekman, R. (2013) Electromagnetic Hypersensitive Finns: Symptoms, Perceived Sources and Treatments, a Questionnaire Study. Pathophysiology, 20, 117-122.

http://dx.doi.org/10.1016/j.pathophys.2013.02.001

\section{The Additional Information}

The details of this case can be observed in the following YouTube video.

Cell Phone and Body Movement. https://www.youtube.com/watch?v=LpUsKAESEd0 
Scientific Research Publishing (SCIRP) is one of the largest Open Access journal publishers. It is currently publishing more than 200 open access, online, peer-reviewed journals covering a wide range of academic disciplines. SCIRP serves the worldwide academic communities and contributes to the progress and application of science with its publication.

Other selected journals from SCIRP are listed as below. Submit your manuscript to us via either submit@scirp.org or Online Submission Portal.
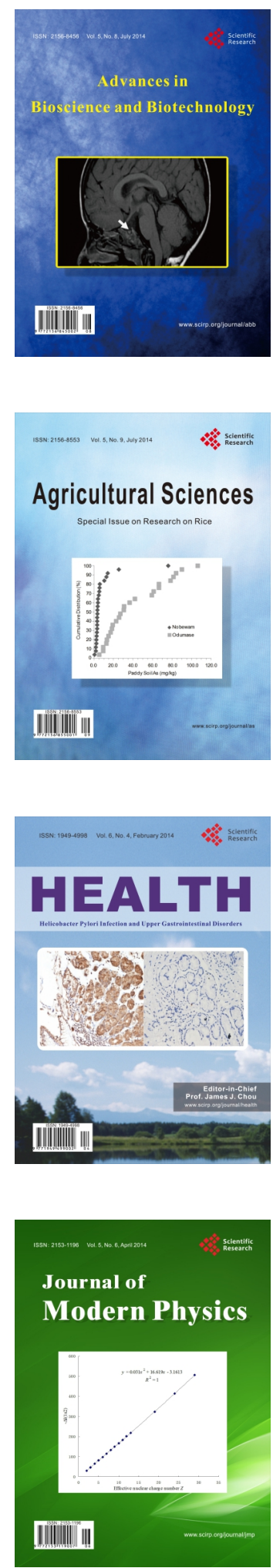
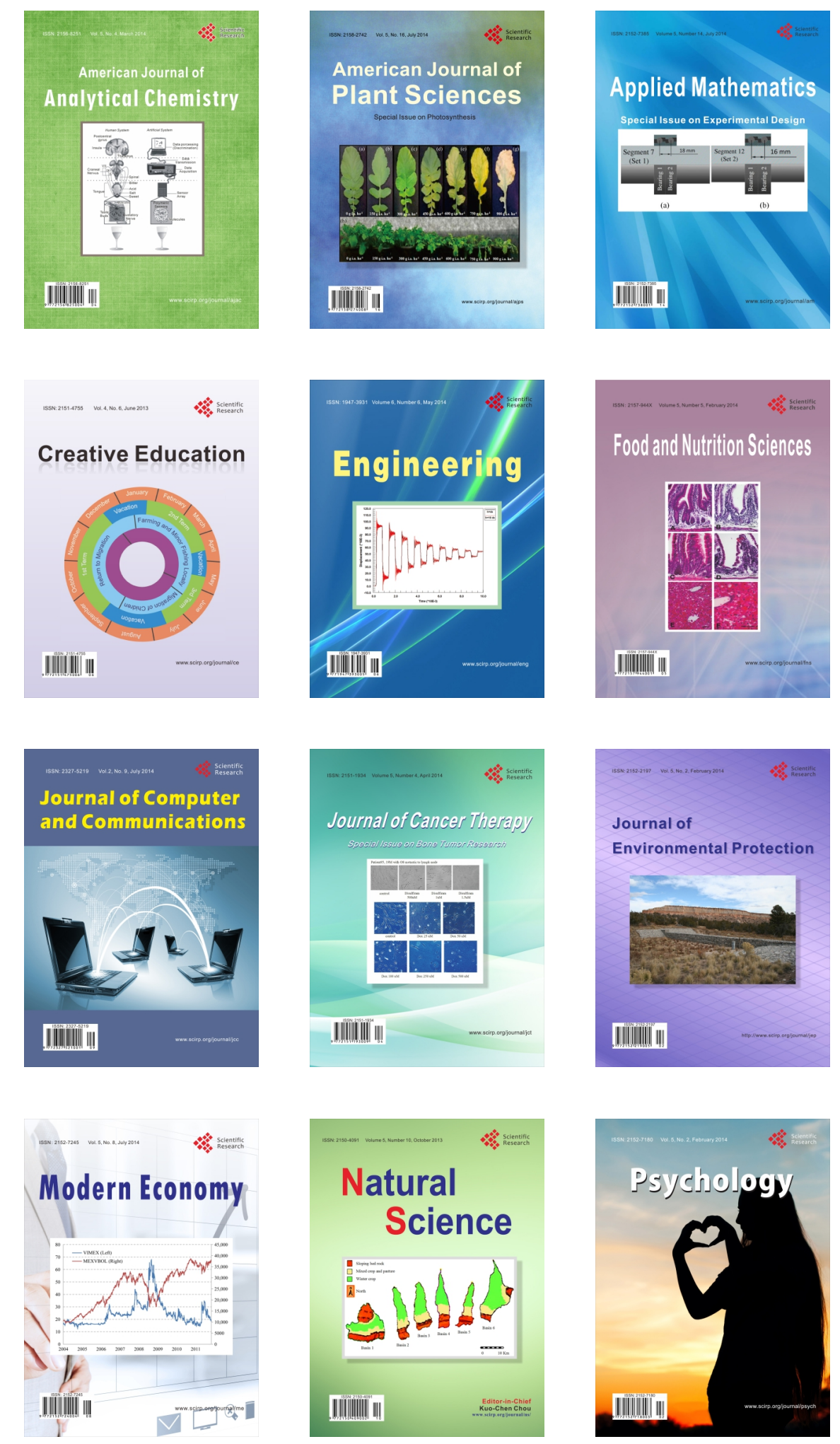